\title{
Mechanochemical Functionalization of Carbon Black at Room Temperature
}

\author{
Desirée Leistenschneider ${ }^{1}$, Katharina Zürbes ${ }^{1}$, Christina Schneidermann $^{1}$, Sven Grätz $^{1}$ (1), \\ Steffen Oswald ${ }^{2}$, Karl Wegner ${ }^{1}$, Benjamin Klemmed ${ }^{3}$, Lars Giebeler $^{2}$ (1), \\ Alexander Eychmüller ${ }^{3}$ and Lars Borchardt 1,* (iD \\ 1 Department of Inorganic Chemistry, Technische Universität Dresden, Bergstraße 66, \\ 01062 Dresden, Germany; desiree.leistenschneider@tu-dresden.de (D.L.); \\ katharina.zuerbes@chemie.tu-dresden.de (K.Z.); christina.schneidermann@tu-dresden.de (C.S.); \\ sven.graetz@tu-dresden.de (S.G.); karl.wegner@tu-dresden.de (K.W.) \\ 2 Institute for Complex Materials, Leibniz Institute for Solid State and Materials Research (IFW) Dresden e.V., \\ Helmholtzstraße 20, 01069 Dresden, Germany; s.oswald@ifw-dresden.de (S.O.); \\ l.giebeler@ifw-dresden.de (L.G.) \\ 3 Physical Chemistry, Technische Universität Dresden, Bergstraße 66b, 01062 Dresden, Germany; \\ benjamin.klemmed@chemie.tu-dresden.de (B.K.); alexander.eychmueller@chemie.tu-dresden.de (A.E.) \\ * Correspondence: lars.borchardt@chemie.tu-dresden.de; Tel.: +49-3514-633-4960
}

Received: 30 January 2018; Accepted: 9 February 2018; Published: 13 February 2018

\begin{abstract}
Carbon nanomaterials such as carbon blacks are intrinsically hydrophobic with limited wettability in aqueous media, thus restricting their potential applications. To improve their hydrophilicity, common methods tend to utilize harmful chemicals and conditions, such as a mixture of $\mathrm{KMnO}_{4}$ and $\mathrm{H}_{2} \mathrm{SO}_{4}$ or a complex and expensive synthesis setup. In our work, we report a simple method to improve the wettability of these materials by a mechanochemical treatment completed within $1 \mathrm{~h}$ at room-temperature utilizing a $\mathrm{NH}_{3}$ solution. Besides increasing the specific surface area of the carbon black from $67 \mathrm{~m}^{2} \cdot \mathrm{g}^{-1}$ up to $307 \mathrm{~m}^{2} \cdot \mathrm{g}^{-1}$, our process also incorporates nitrogen- and oxygen-containing functional groups into the carbon. This reduces the contact angle from $80^{\circ}$ to $30^{\circ}$, confirming an enhanced wettability. Our work presents an easy, fast, and straightforward pathway towards the functionalization of carbon nanomaterials and can be of use in various applications where aqueous wettability is advantageous.
\end{abstract}

Keywords: carbon black; hydrophilization; functionalization; mechanochemistry; one-pot synthesis; room temperature

\section{Introduction}

The application of carbon materials is enormously widespread, ranging from catalysis [1], sorption, and separation [2,3], to energy storage in batteries [4], supercapacitors [5], and fuel cells [6]. The requirements carbons have to meet are strongly dependent on their applications. As electrode materials they have to provide high conductivities and high specific surface areas [7], as support materials in catalysis they have to ensure strong interaction between the surface and the active species [8], and in adsorptive applications such as wastewater purification they have to remove chemicals like heavy metal ions [9] or pharmaceuticals [10] rapidly and to a large extent. Therefore, the porosity and the surface polarity of carbons are key and need to be specifically tailored to the corresponding application. While many synthesis concepts exist for adjusting porosity in carbons, the surface remains mostly non-polar [11]. For many of the abovementioned applications, however, an increase of the surface polarity is required to improve the affinity for metal ions [12] or the wettability [13]. 
Different methods have been reported concerning the introduction of functionalities like amino groups or oxygen-containing groups. Classically, the Brodie and Staudenmaier method utilizes strong oxidizing chemicals like $\mathrm{KClO}_{3}$ and fuming nitric acid [14,15], while the Hummers method uses a mixture of $\mathrm{KMnO}_{4}$ and $\mathrm{H}_{2} \mathrm{SO}_{4}[16,17]$. Carbons can also be functionalized by thermal treatment with oxidizing acids such as $\mathrm{HNO}_{3}$ and $\mathrm{H}_{2} \mathrm{SO}_{4}[18,19]$. On the one hand, these methods require cautious handling due to the highly exothermic reaction, high temperatures, and hazardous chemicals, and they often require extensive washing steps. On the other hand, milder methods like plasma treatment are also commonly applied. In this way, carbon nanotubes, graphite, and porous carbons are surface functionalized, either by $\mathrm{O}_{2}$ plasma [20], above-solution plasma [21], or Ar plasma [22], respectively. Nevertheless, plasma treatment also exhibits environmental issues as a result of the high power input and the extensive technical equipment required.

An alternative method that is prone to introduce functionalities and heteroatoms into a carbon network is based on mechanochemistry [23-26]. Due to the collision of milling balls inside a planetary ball mill, mechanical energies can be utilized to easily break and build chemical bonds [27]. Moreover, mechanochemistry has been shown to enable unexpected reactions, like the dimerization of fullerenes [28]. In addition, reactions can take place within a few minutes, with low technical effort [29] and without the presence of solvents [30,31]. The latter displays a major economic and ecological advantage, since a lot of waste can be avoided [32]. For all of these reasons, the potential use of mechanical energy to economize chemical syntheses should be considered in all disciplines.

In this work, ball milling is utilized as a powerful tool to tailor the porosity and the surface functionalities of carbon black (CB) (Figure 1). CB is a class of graphitic material, which impresses with its high electrical conductivity [33] and low production costs [34]. It is often utilized as a conductive additive in electrodes or functional materials. Nevertheless, the material lacks in wettability and porosity, which compromises its use in aqueous media, especially as an adsorbent for water purification [12] or an additive in polar plastics [35]. Our goal is to quickly and easily functionalize CB under environmentally friendly conditions, i.e., at room temperature in a ball mill without an excess of harmful chemicals. By this treatment, the porosity and the surface polarity are increased. With this study, the range of possible applications of $C B$ is extended and the synthesis of functionalized CB is economized.

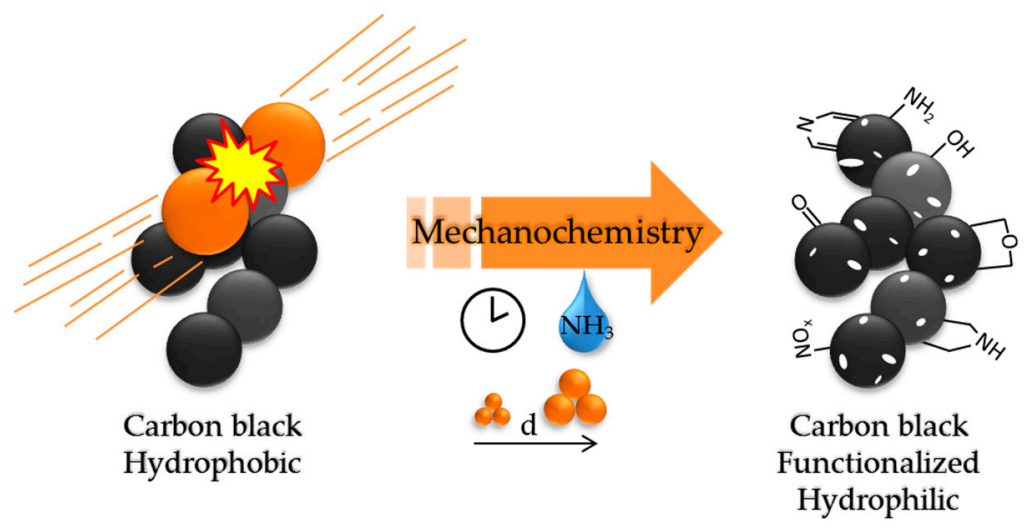

Figure 1. Scheme for the functionalization of carbon black in a ball mill.

\section{Results and Discussion}

\subsection{Impact of Mechanochemical Treatment on the Textural Properties of Pristine CB}

First, the impact of dry milling on the porosity, the carbon content, and the graphitization of non-functionalized CB powder is investigated. If not stated otherwise, $\mathrm{ZrO}_{2}$ milling balls with a diameter of $10 \mathrm{~mm}$ are used. An asterisk indicates that milling balls with a diameter of $15 \mathrm{~mm}$ are used. By milling the powder for $30 \mathrm{~min}$ (CB-0.5), the specific surface area of CB is increased from 
$67 \mathrm{~m}^{2} \cdot \mathrm{g}^{-1}$ to $307 \mathrm{~m}^{2} \cdot \mathrm{g}^{-1}$ (Figure $2 \mathrm{a}$ and Table 1). Prolonging the milling time to $1 \mathrm{~h}(\mathrm{CB}-1)$ and $2 \mathrm{~h}(\mathrm{CB}-2)$ reduces the specific surface area to $63 \mathrm{~m}^{2} \cdot \mathrm{g}^{-1}$ and $64 \mathrm{~m}^{2} \cdot \mathrm{g}^{-1}$, respectively (Figure 2a, ESI (Electronic supporting information) Table S1). It is assumed that, first, carbon bonds are broken by the introduced milling energy, forming oxygen functionalities at the fracture sites, resulting in an enlargement of the surface area due to the wedging of the fragments. However, with an extended energy input, these functionalities lead to new bonding and a collapsing of the porous structure and, in turn, a decrease of the specific surface area. Similar observations have been made by Jeon and coworkers when graphene sheets were milled in the presence of dry ice [24]. By milling the pristine $\mathrm{CB}$ powder for $0.5 \mathrm{~h}$ with milling balls exhibiting a larger diameter of $15 \mathrm{~mm}\left(\mathrm{CB}-0.5^{*}\right)$, the overall energy input is increased in a similar way, consequently leading to the same reduction of the specific surface area as observed for CB milled over longer time periods.

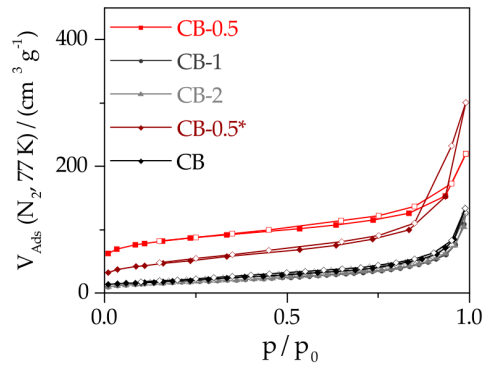

(a)

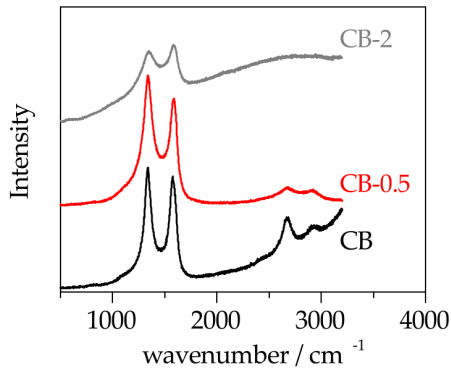

(b)

Figure 2. (a) Nitrogen physisorption isotherms of the milled carbon black (CB) under different conditions and (b) Raman spectra normalized to the intensity of the vibration at $1560 \mathrm{~cm}^{-1}$.

Table 1. Porosity, composition data, and zeta potential of the samples.

\begin{tabular}{|c|c|c|c|c|c|c|c|}
\hline Sample $^{1}$ & $\begin{array}{l}\left.\mathrm{SSA}_{\left(\mathrm{BET}^{2}\right.}{ }^{2} \cdot \mathrm{g}^{-1}\right) \\
\end{array}$ & $\begin{array}{l}\mathrm{V}_{\mathrm{N} 2, \text { total }}{ }^{3 /} \\
\left(\mathrm{cm}^{3} \cdot \mathrm{g}^{-1}\right)\end{array}$ & $\begin{array}{l}\mathrm{V}_{\mathrm{N} 2 \text {,micro }}{ }^{4} / \\
\left(\mathrm{cm}^{3} \cdot \mathrm{g}^{-1}\right)\end{array}$ & $\begin{array}{l}\mathrm{V}_{\mathrm{N} 2 \text {,meso }}{ }^{5 /} \\
\left(\mathrm{cm}^{3} \cdot \mathrm{g}^{-1}\right)\end{array}$ & $\begin{array}{l}\mathrm{V}_{\mathrm{H} 2 \mathrm{O}, \text { total }^{3}}{ }^{3 /} \\
\left(\mathrm{cm}^{3} \cdot \mathrm{g}^{-1}\right)\end{array}$ & $\begin{array}{c}\text { N-Content } \\
\text { wt } \%\end{array}$ & $\begin{array}{c}\text { Zeta Potential }{ }^{7 /} \\
\text { mV }\end{array}$ \\
\hline $\mathrm{CB}$ & 67 & 0.11 & 0.01 & 0.10 & 0.03 & n. d. & -5.5 \\
\hline CB-0.5 & 307 & 0.24 & 0.09 & 0.15 & 0.21 & n. d. & -16.4 \\
\hline CB-1 & 63 & 0.09 & 0.01 & 0.08 & - & - & - \\
\hline CB-2 & 64 & 0.09 & 0.00 & 0.09 & - & - & - \\
\hline NCB-0.51 & 308 & 0.40 & 0.07 & 0.33 & 0.33 & 2.0 & -34.1 \\
\hline NCB- $1_{1}$ & 216 & 0.30 & 0.05 & 0.25 & - & 2.9 & - \\
\hline NCB-2 ${ }_{1}$ & 163 & 0.12 & 0.04 & 0.08 & - & 2.3 & - \\
\hline NCB- $4_{1}$ & 7 & n. d. & n. d. & n. d. & - & 2.2 & - \\
\hline NCB- $0.5_{2}$ & 275 & 0.22 & 0.07 & 0.15 & - & 2.7 & - \\
\hline NCB- $0.5_{3}$ & 267 & 0.29 & 0.06 & 0.23 & - & 2.3 & - \\
\hline
\end{tabular}

${ }^{1}$ Sample code is composed as follows: CB-X, where $\mathrm{X}$ stands for milling time in hours; $\mathrm{NCB}-\mathrm{X}_{\mathrm{y}}$, where $\mathrm{X}$ stands for milling time and y describes the volume of $\mathrm{NH}_{3}$ added: $1=1 \mathrm{~mL}, 2=0.5 \mathrm{~mL}, 3=1.5 \mathrm{~mL} ;{ }^{2}$ determined at $p / p_{0}=0.05-0.2 ;{ }^{3}$ determined at $p / p_{0}=0.94 ;{ }^{4}$ calculated by the cumulative pore volume determined by QSDFT (Quenched solid state density functional theory) with pores smaller than $2 \mathrm{~nm} ;{ }^{5}$ calculated as $\mathrm{V}_{\text {total }}-\mathrm{V}_{\text {micro }}$; ${ }^{6}$ determined by elemental analysis; ${ }^{7}$ determined at $\mathrm{pH} 7$.

To scrutinize structural changes in the carbon network, we conducted Raman spectroscopy (Figure 2b). The spectra show two vibrations typical for carbon materials. The vibration at $1360 \mathrm{~cm}^{-1}$ (D band) is caused by the disordered parts in the carbon network, while the vibration at $1560 \mathrm{~cm}^{-1}$ ( $\mathrm{G}$ band), is due to the graphitic carbon parts [36]. The decrease in intensity of these vibrations with an extension of the grinding time is clearly visible. The $\mathrm{D} / \mathrm{G}$ band ratio is increased from 1.09 (CB) to 1.63 (CB-0.5) during milling, revealing that the graphitic domains are destroyed and disordered parts are formed. With longer milling time, the $\mathrm{D} / \mathrm{G}$ ratio decreases again and a broadening of both bands (increase in FWHM (full width at half maximum)) can be observed. A similar observation was also made by Posudievsky and coworkers synthesizing graphene oxide by a mechanochemical treatment of graphite [37]. Corresponding to the work of Xing and coworkers, who investigated the disorder of graphite caused by mechanochemistry under an inert atmosphere, we assume that the disordering of 
$\mathrm{CB}$ under air is more pronounced and takes already place with shorter milling time of $2 \mathrm{~h}$ [38]. This leads to the broadening of the D and G bands. A detailed table with all D/G band ratios can be found in the supplementary information (Table S1).

A closer look at the functional groups formed during milling was conducted exemplarily for sample CB-0.5 using X-ray photoelectron spectroscopy (XPS). The measurement reveals the presence of C-O-C groups and an oxygen content of $8.7 \mathrm{wt} \%$ (ESI, Tables S2 and S3, Figure S1). This supports the assumption that carbon bonds are broken due to the milling procedure and oxygen is incorporated at the fractured sites. Another effect of the mechanochemical treatment is the modification of the carbon particles' shape (ESI, Figure S6). Counterintuitively, the pristine CB powder with the lower BET surface area consists of small spherical particles, whereas the milled sample CB-0.5 exhibits bulkier agglomerates due to the agglomeration of the smaller particles. We assume that the reason for this is the condensation of the particles due to the presence of oxygen-containing surface groups, leading to a more compact macroscopic shape.

\subsection{Mechanochemical Functionalization of $C B$}

The next target was to functionalize the surface of $C B$ mechanochemically. The sample code has to be read as follows: NCB- $X_{y}$, where NCB stands for nitrogen-functionalized carbon black, $X$ stands for the milling duration, and y describes the added $\mathrm{NH}_{3}$ volume. First, $1 \mathrm{~mL} \mathrm{of} \mathrm{NH}_{3}$ solution $\left(1.4 \mathrm{~mol} \cdot \mathrm{L}^{-1}\right)\left(\mathrm{NCB}-0.5_{1}\right)$ was added to the milling procedure. The specific surface area remains almost unaltered with a value of $308 \mathrm{~m}^{2} \cdot \mathrm{g}^{-1}$ compared to the dry milled sample CB-0.5 (Figure 3a). The total pore volume increases from $0.11 \mathrm{~cm}^{3} \cdot \mathrm{g}^{-1}$ up to $0.40 \mathrm{~cm}^{3} \cdot \mathrm{g}^{-1}$, which is assigned to the formation of mesopores (Table 1). We assume that the incorporation of nitrogen-containing surface functionalities like amino groups leads to condensation reactions caused by the input of mechanochemical energy. For this purpose, the elemental composition of the sample NCB-0.5 1 was investigated by elemental analysis to determine the doping with nitrogen. NCB- $0.5_{1}$ shows a nitrogen content of $2 \mathrm{wt} \%$, whereas the nitrogen content of samples CB and CB- 0.5 are below the detection limit of $1 \mathrm{wt} \%$ (Table 1). The oxygen doping, as well as the identification of the functional groups was done by XPS measurements, showing the presence of amine groups besides pyridinic groups for NCB-0.5 1 (ESI, 1.1). The presence of pyridine-N-oxide groups in sample NCB- $0.5_{1}$ clearly supports the assumption that additional mesopores are formed due to the condensation reaction between the incorporated surface functionalities. XPS measurements also indicate an abrasion of milling material $\left(\mathrm{ZrO}_{2}\right)$ of approximately $5 \mathrm{wt} \%$ (ESI, Table S2).

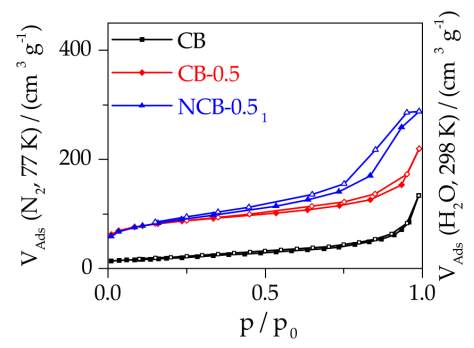

(a)

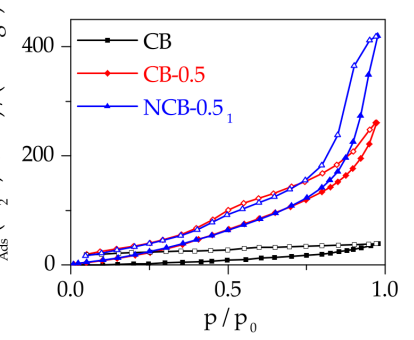

(b)

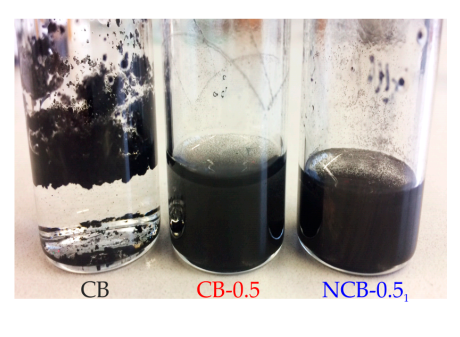

(c)

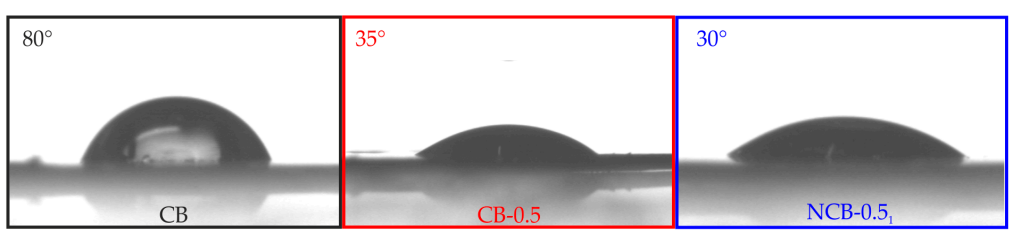

(d)

Figure 3. (a) Nitrogen physisorption at $77 \mathrm{~K}$; (b) water adsorption isotherm at $298 \mathrm{~K}$; (c) image of the samples CB, CB-0.5, and NCB-0.5 1 dispersed in pure water; and (d) contact angle measurement of the different $C B$ samples. 
The functionalization with heteroatoms such as nitrogen and oxygen influences the hydrophilicity of the carbon material, which we further investigated by contact angle measurements (Figure 4), $\mathrm{H}_{2} \mathrm{O}$ physisorption (Figure $3 \mathrm{~b}$ ), and measurement of the Zeta potential (Table 1). The mechanochemical treatments, in particular the pure grinding and $\mathrm{NH}_{3}$-assisted grinding, lead to the reduction of the Zeta potential from $-5.5 \mathrm{mV}$ to at least $-34.1 \mathrm{mV}$ evoked by the $\mathrm{NH}_{3}$ treatment. In general, the carbon particles show a negative Zeta potential, according to the pyridine- $N$-oxidic functionalities and other negatively charged surface functionalities [39]. Furthermore, a dispersion is considered to be stable with a Zeta potential below $-30 \mathrm{mV}$ [40]. Thus, $\mathrm{NH}_{3}$ functionalization results in a carbon material with good aqueous wettability.

This assumption is further confirmed by the contact angle measurement (Figure 3d), showing that NCB- $0.5_{1}$ exhibits the lowest contact angle of $30^{\circ}$ while the untreated CB has a contact angle of $80^{\circ}$. Also, the pure grinding (CB-0.5) leads to a better dispersible carbon material with a contact angle of $35^{\circ}$ and a Zeta potential of $-16.4 \mathrm{mV}$. The better wetting due to the surface functionalization is already visible when the samples are dispersed in pure water (Figure 3c).

Furthermore, for an evaluation of the affinity for water, water adsorption experiments were carried out (Figure 3c). The mechanochemically treated samples CB-0.5 and NCB-0.5 1 show type V isotherms. The isotherm of the untreated $C B$ indicates no interaction with water, leading to a low water uptake. NCB-0.5 $5_{1}$ and CB-0.5 show a comparable initial water uptake, whereas the initial uptake of sample NCB- 0.51 is slightly shifted to lower relative pressures compared to CB-0.5. Regarding the adsorbed amount of water at the full saturation at $p / p_{0}=0.95$, NCB- $0.5_{1}$ has the highest water adsorption capacity, attributed to the increased pore volume estimated by nitrogen physisorption experiments (Table 1).

As NCB- $0.5_{1}$ has the highest surface area and nitrogen content, the influence of two selected milling parameters on these properties were examined in particular. The two varied milling parameters, namely the milling time and the volume of added $\mathrm{NH}_{3}$, influence the overall energy input into the carbon material during the mechanochemical treatment [41]. Nitrogen physisorption experiments show that the extension of the milling time also leads to a reduction of the specific surface area (Figure 4a). This can be attributed to the destruction of previously formed mesopores during the treatment, what clearly follows the findings of the milling without $\mathrm{NH}_{3}$ solution (see Section 2.1). It can be assumed that prolonging the milling time is disadvantageous to the porosity and does not increase the nitrogen content significantly.

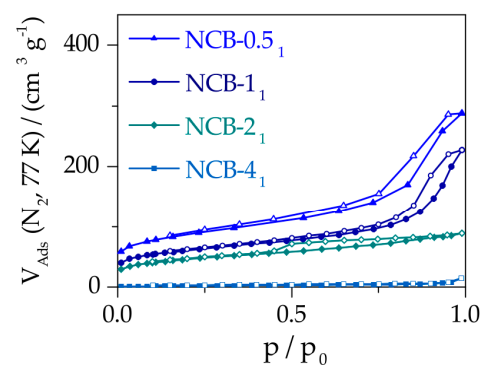

(a)

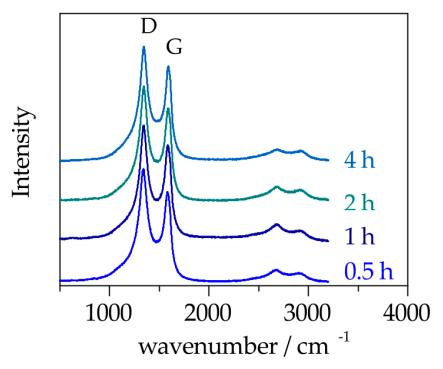

(b)

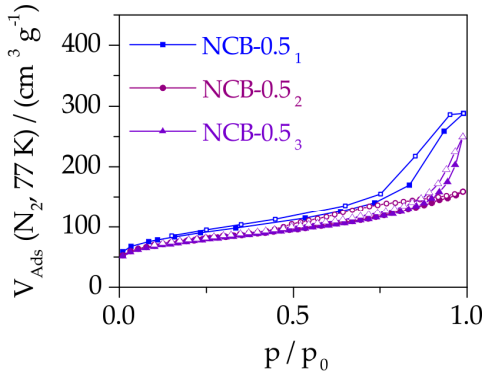

(c)

Figure 4. (a) Nitrogen physisorption isotherms of the $\mathrm{NH}_{3}$-functionalized carbon black milled with different durations and (b) Raman spectra; as well as (c) nitrogen physisorption isotherms of the $\mathrm{NH}_{3}$-functionalized carbon black with different volumes of $\mathrm{NH}_{3}$ solution.

Contrary to the samples that were milled without any additive (CB-0.5, CB-1, and CB-2), the FWHM of the two characteristic vibrations at $1360 \mathrm{~cm}^{-1}$ and $1560 \mathrm{~cm}^{-1}$ for the NCB samples do not change with a longer milling time (Figure $4 \mathrm{~b}$ ). This is caused by the milder milling conditions of the liquid-assisted approach [41]. The variation of the amount of $\mathrm{NH}_{3}$ added to the CB powder leads to a minor reduction of the specific surface area from $307 \mathrm{~m}^{2} \cdot \mathrm{g}^{-1}$ to $225 \mathrm{~m}^{2} \cdot \mathrm{g}^{-1}$ and $267 \mathrm{~m}^{2} \cdot \mathrm{g}^{-1}$ 
for NCB- $0.5_{2}$ and NCB-0.53, respectively (Table 1 and Figure 4c). By changing the amount of liquid, the content of incorporated nitrogen is not altered, staying constant at around $2.5 \mathrm{wt} \%$, which is proven by elemental analysis (Table 1 and Figure S6). Thus, the most promising combination of a high specific surface area and a nitrogen content of $2 \mathrm{wt} \%$ was achieved by treating CB for $30 \mathrm{~min}$ with $10 \mathrm{~mm} \mathrm{ZrO}_{2}$ balls and the addition of $1 \mathrm{~mL} \mathrm{NH}_{3}$ solution (NCB-0.51).

\section{Materials and Methods}

\subsection{General Techniques}

Ammonium hydroxide solution $\left(\mathrm{NH}_{3}, 25 \mathrm{Vol} \%\right.$, purity: pro analysis) was purchased from Sigma-Aldrich (St. Louis, MO, USA). Carbon black (acetylene black, CB, purity: 99.9\%) was purchased from abcr GmbH (Karlsruhe, Germany).

Elemental analysis was carried out on a vario MICRO cube Elemental Analyzer by Elementar Analysatorsysteme $\mathrm{GmbH}$ in the CHNS mode. The samples were activated at $200{ }^{\circ} \mathrm{C}$ prior to the measurement.

Nitrogen physisorption experiments were executed with a Quadrasorb EVO/SI from Quantachrome (Odelzhausen, Germany) at $-196^{\circ} \mathrm{C}$. Prior to the measurements, the samples were degassed for at least $24 \mathrm{~h}$ at $150{ }^{\circ} \mathrm{C}$ under vacuum. The specific surface area was calculated in a relative pressure range of $0.05-0.2$ according to the Brunauer-Emmett-Teller theory. Total pore volumes were determined at a relative pressure of 0.94 . Pore size distributions were determined by applying the quenched solid state density functional theory (QSDFT) adsorption model for slit-, cylindrical-, and spherical-shaped pores at $-196^{\circ} \mathrm{C}$. Micropore volumes were calculated from the cumulative pore volume at $2 \mathrm{~nm}$ by QSDFT as well.

Water vapor adsorption was carried out at $25^{\circ} \mathrm{C}$ using an Autosorb iQ from Quantachrome after vacuum drying at $150^{\circ} \mathrm{C}$ for $24 \mathrm{~h}$.

Raman spectra were carried out with a RM-2000 from Renishaw (Wotton-under-Edge, UK) with a $50 \times$ objective $\left(N_{\mathrm{A}}=0.75\right)$ and a wavelength of $532 \mathrm{~nm}$.

Scanning electron microscope images were taken with an SU8020 from Hitachi (Chiyoda, Japan) at an acceleration voltage of $2 \mathrm{kV}$.

Zeta potentials were measured with a Zetasizer nano from Malvern instruments (Malvern, UK) at a $\mathrm{pH}$ value of 7 with the electrophoreses technique.

XPS experiments were performed on a Physical Electronics PHI 5600 CI with monochromated Al $\mathrm{K} \alpha$ radiation $(1486.7 \mathrm{eV})$ at $350 \mathrm{~W}$ in an energy range of $0-1200 \mathrm{eV}$. The spectrometer was equipped with a hemispherical analyzer allowing high-sensitivity and high-resolution experiments. Energy scale and binding energy were calibrated with $\mathrm{Cu}$ and $\mathrm{Au}$ foils at the binding energies of $\mathrm{Cu} 2 \mathrm{p}_{3 / 2}(932.67 \mathrm{eV})$ and $\mathrm{Au} 4 \mathrm{f}_{7 / 2}(84.00 \mathrm{eV})$, respectively. Base pressure was realized at $1 \times 10^{-9}-1 \times 10^{-8} \mathrm{mbar}$. The survey spectra (wide scans) were collected with a pass energy of $90 \mathrm{eV}$ and a step size of $0.4 \mathrm{eV}$. High-resolution spectra (narrow scans) were taken with a pass energy of $29 \mathrm{eV}$ and a step size of $0.1 \mathrm{eV}$. For all experiments powder samples were used as received. Elemental concentrations were calculated from the survey and high-resolution spectra by use of corrected relative element sensitivity factors. Fits were performed with the PHI Multipak software package (version 9.3, ULVAC-PHI, Chanhassen, MN, USA) by applying a Shirley background algorithm on the non-normalized spectra. Batch fit mode was applied for all carbon and oxygen HR spectra, as well as for CB-0.5 and NCB-0.51.

\subsection{Synthesis}

For all samples, $1.2 \mathrm{~g}$ carbon black were first milled in a 45-mL zirconium oxide milling cup for $30 \mathrm{~min}$ at $800 \mathrm{rpm}$ in a Fritsch Pulverisette 7 premium line planetary ball mill. Twenty $\mathrm{ZrO}_{2}$ balls with a diameter of $10 \mathrm{~mm}$ were used. The sample obtained after the dry milling was CB-0.5. Adding $1 \mathrm{~mL}$ of $\mathrm{NH}_{3}$-solution $\left(1.47 \mathrm{~mol} \cdot \mathrm{L}^{-1}\right)$ and milling for further $30 \mathrm{~min}$ under the abovementioned conditions led to NCB- $0.5_{1}$. After the mechanochemical treatment, the obtained carbon was washed at least three 
times with water until the sample was $\mathrm{pH}$-neutral and centrifuged. The carbon was then washed with ethanol once and dried at $80^{\circ} \mathrm{C}$ overnight.

\section{Conclusions}

In this work, a straightforward mechanochemical pathway is described for improving the porosity and wettability of a carbon black material. By grinding, oxygen-containing surface functionalities can be introduced directly and the surface area can be increased from $67 \mathrm{~m}^{2} \cdot \mathrm{g}^{-1}$ to $307 \mathrm{~m}^{2} \cdot \mathrm{g}^{-1}$. In order to introduce nitrogen-containing groups into the carbon, a simple method was shown where the material was milled in the presence of ammonia, resulting in a nitrogen content of $2.5 \mathrm{wt} \%$. By XPS measurements, the added surface functionalities were identified as amine and pyridine- $N$-oxide groups, leading to a better wettability of the carbon material regarding a small contact angle of $30^{\circ}$ and a Zeta potential of $-34.1 \mathrm{mV}$ in neutral $\mathrm{pH}$. This approach significantly broadens the applicability of carbon blacks and additionally economizes the post-synthetic modification compared to well-known state of the art methods.

Supplementary Materials: The following are available online at www.mdpi.com/2311-5629/4/1/14/s1, Table S1. Ratio of the vibrations of the D and G Band calculated as the ratio of the peak areas fitted as Gaussian; Table S2. Element concentrations from the high resolution spectra; Table S3. The signal-contributing carbon species calculated from the $C 1$ s high resolution spectra; Figure S1. (a) Fitted C 1s spectrum of CB and (b) fitted C 1s spectrum of CB-0.5. Blue $=\mathrm{C}-\mathrm{C}$; green $=\mathrm{C}-\mathrm{O}$; dark yellow $=\mathrm{O}-\mathrm{C}-\mathrm{O}$; turquois $=\mathrm{O}-\mathrm{C}=\mathrm{O}$; magenta $=\pi-\pi^{*} ;$ Figure S2 . Fitted C 1s spectrum of NCB-0.5 . Blue $=\mathrm{C}-\mathrm{C}$; green $=\mathrm{C}-\mathrm{O}$; dark yellow $=\mathrm{O}-\mathrm{C}-\mathrm{O}$; turquois $=\mathrm{O}-\mathrm{C}=\mathrm{O}$; magenta $=$ $\pi-\pi^{*}$; Table S4. The signal-contributing oxygen species calculated from the O 1s high resolution spectra; Figure S3. (a) $\mathrm{O} 1 \mathrm{~s}$ signal of $\mathrm{CB}$ and (b) $\mathrm{O}$ 1s signal of $\mathrm{CB}-0.5$. Blue $=\mathrm{C}=\mathrm{O}$; green $=\mathrm{C}-\mathrm{OH} / \mathrm{C}-\mathrm{O}-\mathrm{C}$; dark yellow $=$ shake-up satellite; Figure S4. O 1s signal of NCB-0.5. Blue = C=O; green = C-OH $/ \mathrm{C}-\mathrm{O}-\mathrm{C}$; dark yellow = shake-up satellite; Table S5. The signal-contributing nitrogen species calculated from the N 1s high resolution spectra; Figure S5. (a) N 1s signal of CB-0.5 and (b) N 1s signal of NCB-0.5. Green = pyridinic groups; blue = imine/amide/amine groups; dark yellow = pyridin-N-oxide; Table S6. Elemental composition determined by elemental analysis; Figure S6. Content of incorporated nitrogen correlated with the volume of added $\mathrm{NH}_{3}$; Figure S7. SEM images of the sample CB, CB-0.5 and NCB-0.5 1 .

Acknowledgments: Desirée Leistenschneider, Christina Schneidermann, Sven Grätz, and Lars Borchardt gratefully acknowledge the Federal Ministry of Education and Research (Bundesministerium für Bildung und Forschung, BMBF) for support of the Mechanocarb project (award number 03SF0498). Desirée Leistenschneider extends thanks to Sebastian Ehrling for the SEM measurements. We also thank Steffi Kaschube (IFW) for technical assistance with the XPS experiments.

Author Contributions: Desirée Leistenschneider, Lars Borchardt, and Katharina Zürbes conceived and designed the experiments and analyzed the data; Christina Schneidermann and Sven Grätz performed physisorption experiments; Karl Wegner performed the elemental analysis; Benjamin Klemmed performed Raman spectroscopy; Steffen Oswald and Lars Giebeler performed XPS measurements and data analysis; Alexander Eychmüller contributed analysis tools; Desirée Leistenschneider and Katharina Zürbes wrote the paper.

Conflicts of Interest: The authors declare no conflict of interest.

\section{References}

1. Rodríguez-Reinoso, F. The role of carbon materials in heterogeneous catalysis. Carbon 1998, 36, $159-175$. [CrossRef]

2. Sawant, S.Y.; Munusamy, K.; Somani, R.S.; John, M.; Newalkar, B.L.; Bajaj, H.C. Precursor suitability and pilot scale production of super activated carbon for greenhouse gas adsorption and fuel gas storage. Chem. Eng. J. 2017, 315, 415-425. [CrossRef]

3. Kim, S.; Chen, L.; Johnson, J.K.; Marand, E. Polysulfone and functionalized carbon nanotube mixed matrix membranes for gas separation: Theory and experiment. J. Membr. Sci. 2007, 294, 147-158. [CrossRef]

4. Oschatz, M.; Thieme, S.; Borchardt, L.; Lohe, M.R.; Biemelt, T.; Brueckner, J.; Althues, H.; Kaskel, S. A new route for the preparation of mesoporous carbon materials with high performance in lithium-sulphur battery cathodes. Chem. Commun. 2013, 49, 5832-5834. [CrossRef] [PubMed]

5. Schneidermann, C.; Jäckel, N.; Oswald, S.; Giebeler, L.; Presser, V.; Borchardt, L. Solvent-Free Mechanochemical Synthesis of Nitrogen-Doped Nanoporous Carbon for Electrochemical Energy Storage. ChemSusChem 2017, 10, 2416-2424. [CrossRef] [PubMed] 
6. Maiyalagan, T.; Maheswari, S.; Saji, V.S. Electrocatalysts for Low Temperature Fuel Cells: Fundamentals and Recent Trends; Wiley-VCH: Weinheim, Germany, 2017; ISBN 9783527341320.

7. Frackowiak, E. Carbon materials for supercapacitor application. Phys. Chem. Chem. Phys. 2007, 9, $1774-1785$. [CrossRef] [PubMed]

8. Oschatz, M.; Hofmann, J.P.; van Deelen, T.W.; Lamme, W.S.; Krans, N.A.; Hensen, E.J.M.; de Jong, K.P. Effects of the Functionalization of the Ordered Mesoporous Carbon Support Surface on Iron Catalysts for the Fischer-Tropsch Synthesis of Lower Olefins. Chem CatChem 2017, 9, 620-628. [CrossRef] [PubMed]

9. Zhou, D.-M.; Wang, Y.-J.; Wang, H.-W.; Wang, S.-Q.; Cheng, J.-M. Surface-modified nanoscale carbon black used as sorbents for $\mathrm{Cu}(\mathrm{II})$ and $\mathrm{Cd}(\mathrm{II})$. J. Hazard. Mater. 2010, 174, 34-39. [CrossRef] [PubMed]

10. Tian, W.; Zhang, H.; Duan, X.; Sun, H.; Tade, M.O.; Ang, H.M.; Wang, S. Nitrogen-and Sulfur-Codoped Hierarchically Porous Carbon for Adsorptive and Oxidative Removal of Pharmaceutical Contaminants. ACS Appl. Mater. Interfaces 2016, 8, 7184-7193. [CrossRef] [PubMed]

11. Borchardt, L.; Oschatz, M.; Kaskel, S. Tailoring porosity in carbon materials for supercapacitor applications. Mater. Horiz. 2014, 1, 157-168. [CrossRef]

12. Daus, B.; Wennrich, R.; Weiss, H. Sorption materials for arsenic removal from water: A comparative study. Water Res. 2004, 38, 2948-2954. [CrossRef] [PubMed]

13. Pandolfo, A.G.; Hollenkamp, A.F. Carbon properties and their role in supercapacitors. J. Power Sources 2006, 157, 11-27. [CrossRef]

14. Brodie, B.C. XIII. On the Atomic Weight of Graphite. Philos. Trans. R. Soc. Lond. 1859, 149, 249-259. [CrossRef]

15. Staudenmaier, L. Verfahren zur Darstellung der Graphitsäure. Berichte Dtsch. Chem. Ges. 1898, 31, $1481-1487$. [CrossRef]

16. Hummers, W.S.; Offeman, R.E. Preparation of Graphitic Oxide. J. Am. Chem. Soc. 1958, 80, 1339. [CrossRef]

17. Marcano, D.C.; Kosynkin, D.V.; Berlin, J.M.; Sinitskii, A.; Sun, Z.; Slesarev, A.; Alemany, L.B.; Lu, W.; Tour, J.M. Improved Synthesis of Graphene Oxide. ACS Nano 2010, 4, 4806-4814. [CrossRef] [PubMed]

18. Borah, D.; Satokawa, S.; Kato, S.; Kojima, T. Surface-modified carbon black for As(V) removal. J. Colloid Interface Sci. 2008, 319, 53-62. [CrossRef] [PubMed]

19. Borah, D.; Satokawa, S.; Kato, S.; Kojima, T. Sorption of As(V) from aqueous solution using acid modified carbon black. J. Hazard. Mater. 2009, 162, 1269-1277. [CrossRef] [PubMed]

20. Zhang, X.; Lei, L.; Xia, B.; Zhang, Y.; Fu, J. Oxidization of carbon nanotubes through hydroxyl radical induced by pulsed $\mathrm{O}_{2}$ plasma and its application for $\mathrm{O}_{2}$ reduction in electro-Fenton. Electrochim. Acta 2009, 54, 2810-2817. [CrossRef]

21. Hoshino, S.; Kawahara, K.; Takeuchi, N. Hydrophilization of graphite using plasma above/in a solution. Japan. J. Appl. Phys. 2017, 57, 0102B1. [CrossRef]

22. Kim, E.-S.; Deng, B. Fabrication of polyamide thin-film nano-composite (PA-TFN) membrane with hydrophilized ordered mesoporous carbon (H-OMC) for water purifications. J. Membr. Sci. 2011, 375, 46-54. [CrossRef]

23. Xue, Y.; Chen, H.; Qu, J.; Dai, L. Nitrogen-doped graphene by ball-milling graphite with melamine for energy conversion and storage. 2D Mater. 2015, 2, 044001. [CrossRef]

24. Jeon, I.-Y.; Shin, Y.-R.; Sohn, G.-J.; Choi, H.-J.; Bae, S.-Y.; Mahmood, J.; Jung, S.-M.; Seo, J.-M.; Kim, M.-J.; Wook Chang, D.; et al. Edge-carboxylated graphene nanosheets via ball milling. Proc. Natl. Acad. Sci. USA 2012, 109, 5588-5593. [CrossRef] [PubMed]

25. Xu, J.; Shui, J.; Wang, J.; Wang, M.; Liu, H.-K.; Dou, S.X.; Jeon, I.-Y.; Seo, J.-M.; Baek, J.-B.; Dai, L. Sulfur-Graphene Nanostructured Cathodes via Ball-Milling for High-Performance Lithium-Sulfur Batteries. ACS Nano 2014, 8, 10920-10930. [CrossRef] [PubMed]

26. Jeon, I.-Y.; Choi, H.-J.; Ju, M.J.; Choi, I.T.; Lim, K.; Ko, J.; Kim, H.K.; Kim, J.C.; Lee, J.-J.; Shin, D.; et al. Direct nitrogen fixation at the edges of graphene nanoplatelets as efficient electrocatalysts for energy conversion. Sci. Rep. 2013, 3, 2260. [CrossRef] [PubMed]

27. Do, J.-L.; Friščić, T. Mechanochemistry: A Force of Synthesis. ACS Cent. Sci. 2017, 3, 13-19. [CrossRef] [PubMed]

28. Zhu, S.-E.; Li, F.; Wang, G.-W. Mechanochemistry of fullerenes and related materials. Chem. Soc. Rev. 2013, 42, 7535-7570. [CrossRef] [PubMed] 
29. Leistenschneider, D.; Jäckel, N.; Hippauf, F.; Presser, V.; Borchardt, L. Mechanochemistry-assisted synthesis of hierarchical porous carbons applied as supercapacitors. Beilstein J. Org. Chem. 2017, 13, 1332-1341. [CrossRef] [PubMed]

30. Troschke, E.; Grätz, S.; Lübken, T.; Borchardt, L. Mechanochemical Friedel-Crafts Alkylation-A Sustainable Pathway towards Porous Organic Polymers. Angew. Chem. 2017, 56, 6859-6863. [CrossRef] [PubMed]

31. Grätz, S.; Borchardt, L. A polycondensation reaction between a diamine and a dialdehyde in a ball mill. RSC Adv. 2016, 6, 64799-64802. [CrossRef]

32. James, S.L.; Adams, C.J.; Bolm, C.; Braga, D.; Collier, P.; Friščić, T.; Grepioni, F.; Harris, K.D.M.; Hyett, G.; Jones, W.; et al. Mechanochemistry: Opportunities for new and cleaner synthesis. Chem. Soc. Rev. 2012, 41, 413-447. [CrossRef] [PubMed]

33. Donnet, J.-B.; Bansal, R.C.; Wang, M.-J. Carbon Black: Science and Technology, 2nd ed.; Marcel Dekker: New York, NY, USA, 1993; ISBN -0-8247-8975-X.

34. McKetta, J.J., Jr. Encyclopedia of Chemical Processing and Design: Volume 6; Marcel Dekker: New York, NY, USA, 1978; ISBN 0-8247-2456-9.

35. Park, S.-J.; Seo, M.-K.; Nah, C. Influence of surface characteristics of carbon blacks on cure and mechanical behaviors of rubber matrix compoundings. J. Colloid Interface Sci. 2005, 291, 229-235. [CrossRef] [PubMed]

36. Ferrari, A.C.; Robertson, J. Interpretation of Raman spectra of disordered and amorphous carbon. Phys. Rev. B 2000, 61, 14095-14107. [CrossRef]

37. Posudievsky, O.Y.; Khazieieva, O.A.; Koshechko, V.G.; Pokhodenko, V.D. Preparation of graphene oxide by solvent-free mechanochemical oxidation of graphite. J. Mater. Chem. 2012, 22, 12465-12467. [CrossRef]

38. Xing, T.; Li, L.H.; Hou, L.; Hu, X.; Zhou, S.; Peter, R.; Petravic, M.; Chen, Y. Disorder in ball-milled graphite revealed by Raman spectroscopy. Carbon 2013, 57, 515-519. [CrossRef]

39. Cai, K.; Frant, M.; Bossert, J.; Hildebrand, G.; Liefeith, K.; Jandt, K.D. Surface functionalized titanium thin films: Zeta-potential, protein adsorption and cell proliferation. Colloids Surf. B Biointerfaces 2006, 50, 1-8. [CrossRef] [PubMed]

40. Hunter, R.J. Zeta Potential in Colloid Science: Principles and Applications; Academic Press: Cambridge, MA, USA, 2013; ISBN 9781483214085.

41. Bowmaker, G.A. Solvent-assisted mechanochemistry. Chem. Commun. 2013, 49, 334-348. [CrossRef] [PubMed] 